\title{
Navigating Emotional Waters in Schools: Becoming an Emotionally Adaptable Leader*
}

\author{
Rick Ginsberg \\ Ph.D., University of Kansas, ORCID ID: 0000-0001-7109-0144 \\ Email: ginsberg@ku.edu
}

\begin{abstract}
Emotions impact leaders in multiple ways. The current pandemic has exacerbated the stress on all school personnel and the emotional impact can impact health and work performance. While research has examined workplace related emotions for years, the growth of the concept of emotional intelligence spurred greater interest on the impact of emotions on employee and leader performance. But few studies have specifically considered the impact of emotions on leaders given the roles and duties they perform (Ginsberg \& Davies, 2007; Ginsberg and Multon, 2011a: Ginsberg \& Multon, 2011b). While leadership studies suggest differing styles and approaches depending on circumstances, climate and conditions, research has not considered the kind of leadership approaches relevant for leaders impacted by the emotions they deal with daily, their emotionally-laden reality. This study examines the research on emotions, emotional intelligence, and the work-related tasks in schools that spark emotional reactions. Then, following a discussion of leadership studies on emotional intelligence, transformational leadership, resiliency and related concepts, complexity leadership, crisis and cutback management, and several recent leadership approaches related to improving performance, a framework is offered for becoming an emotionally adaptable leader. The paper concludes with ideas for short-term coping and long-term thriving for emotionally adaptable leaders.
\end{abstract}

Key words: Leadership, emotions, emotional intelligence, COVID-19.

\section{Introduction}

The Covid19 global pandemic instigated significant stress for people in many countries around the world. Stress levels no doubt differ based on a number of variables including the strategy and cohesiveness of the response the country employed. In schools, all stakeholders - students, parents, teachers, administrators, other staff members - are affected. The emotional impact of the unknown and uncertainty involved has likely taken a toll on everyone. The unknowns associated with the effectiveness of instruction, the multiple considerations for determining which approach best fits differing schools, and all the health-associated concerns add to the complexity in the environment. In addition, with schools planning to teach remotely and children staying at home, the traditional role for schools of serving as child care support for parents who work was impacted. Rand's American Educator Panel Survey found that many students were difficult to even contact once schools closed, with $70.7 \%$ of elementary, and only $47.5 \%$ of secondary teachers reporting that they were able to contact all or almost all of their students (Hamilton, Kaufman \& Dilberti, 2020). Kraft \& Simon (June 24, 2020) surveyed teachers in nine U.S. states and found concerns with teacher well-being, student loss of learning and exacerbated achievement gaps among students from differing racial and socio-economic groups.

For those in leadership roles in all fields affected by the pandemic, conceiving the right response is difficult. There is no guidebook. However, crisis leadership and management has been studied and analyzed across an array of situations (e.g. - Coombs, 2007; Pearson \& Clair, 1998; Smits \& Ally, 2003; Teo, Lee \& Lim, 2017; Mitroff et al., 2006). James and Wooten (2005) differentiated between sudden and smoldering crises, with sudden crises being those unexpected events that the leaders had no control over. The pandemic clearly falls in that category. However, as they explained in writing about the business community, "Nevertheless, firm leadership is still expected to resolve the crisis, and any displays of empathy become short-lived if stakeholders perceive firm leadership as mishandling the execution of the crisis response" (p. 143)." Whether the crisis be a pandemic or some other natural disaster or catastrophe, leaders are the ones caught in the vise of needing to orchestrate solutions. Writing about leadership wisdom, Ellis (July 6, 2020), from the University of Chicago's Center for Practical Wisdom, described the challenges as follows:

"We live and work in an age of extreme uncertainty and disruption. Leaders today face the complex systematic challenges of a global pandemic, racial inequality, climate change, and 
economic uncertainty. More than in recent memory people seek coherence, empathy, guidance and support (p. 1)."

What is certain is that the response to the current situation is emotionally laden and impacting those required to lead through the storm. Emotions have impacts on individual behavior, as Ashkanasy \& Dorris (2017) explained, "...positive emotions are pre-requisites for well-being, whereas negative emotions send a signal to the individual that a challenging situation exists that needs to be addressed" (p. 68). While the pandemic is certainly a dire situation that workers and leaders are contending with today, the issue of emotions and their impact on the work world has emerged as a central area for examination since all workplaces involve varying emotions (Ashkansay \& Dorris, 2017). Indeed, Pekrun \& Frese (1992) argued that workplace emotions can be categorized in two ways - the valence (e.g. positive versus negative emotions) and the focus (task-related versus social related).

It is clear that emotions can have both internal manisfestations (e.g. subjective feelings), external manisfestations (e.g. physical and physiological reactions) (Ashkansay \& Dorris, 2017), as well as impact work-related performance (Bellet, De Neve \& Ward, 2020), and cause significant emotional work and labor for those affected (Hochschild, 1983). The purpose of this paper is to specifically explore the kind of leadership approaches needed for school leaders to successfully contend with the myriad of emotions inherent in school settings. More specifically, in recent years many initiatives in schools such as promoting socio-emotional learning have grown in intensity, while at the same time numbers of research studies have focused on the importance of attending to emotions in the workplace (Edelman \& van Knippenberg, 2018; Ashkanasay \& Dorris, 2017; Ashforth \& Humphrey, 1995). However, even with the increased focused on emotions, the specific burdens and impact emotions have on leaders themselves isn't thoroughly examined. All those in schools bring their emotional selves to the school-house gate. Leaders in schools need to address all these emotions for their staff, students and personal benefit while also attending to curricular and performance concerns.

The argument here is that leaders need to learn to become emotionally adaptable given the emotional reality that school leaders confront. This emotional adaptability is important for performance success and leadership sustainability. While this need has become more apparent in the current pandemic environment (e.g. $45 \%$ of secondary school principals in a U.S. survey indicated they have considered or moved up retirement plans due to the pandemic, Farrace, 2020), this notion of emotional adaptability is consistent with research on the importance of emotional intelligence and leadership resilience for workplace success (Stoddard, 2020; Edelman \& van Knippenberg, 2018; Rathore, Chadha \& Rana, 2017; Goleman, 1998b). Indeed, research focused on clinical radiology in medicine emphasizing mindfulness suggested that shielding ourselves from emotional and other discomfort leaves us, "out of touch with the reality of our experience, and our capacity for discernment, wellness, and wise choices in determining the course of our lives deteriorate" (Levey \& Levey, 2019, p. 739). Becoming emotionally adaptable can help leaders contend with the potential impact of all the emotional events and episodes affecting them, as unchecked or ignored emotional experiences may have negative consequences.

This paper begins with a discussion of emotions and emotional intelligence in work settings, then focuses on how this is developing in schools given the growing call for preparation in socio-emotional learning. This is followed by an examination of the emotional triggers inherent in school organizations, with some analysis of the impact of the Covid19 pandemic. Then, with the pandemic as the contextual frame, a description is offered for an approach to leadership appropriate for the emotional milieu and emotional impact that leaders endure - called becoming an emotionally adaptable leader (EAL). The paper ends with some ideas for leaders to better cope with and sustain themselves given the emotions they naturally confront.

\section{Emotions, Emotional Intelligence and Schools}

Emotions are powerful. They affect nearly all facets of human life. People tend to behave in ways geared towards maximizing positive and minimizing negative emotions (Frijda, 1992). Emotions are reflected in motor behaviors and in human physiological responses (Ashkanasy \& Dorris, 2017). Existing research, for example, discusses the impact of emotions on marketing and advertising effectively (Hamelin et al., (2017), on cardiovascular heart disease (Tennant \& McLean, (2001), and on learning and memory (Tyng et al., 2017), to name just a small number of the areas that have been examined. Fear, the most primal of emotions, has been described as a potent component of American culture (Glassner, 1999). It has been studied as an essential part of American politics (Robin, 2004) and the politics of education (Ginsberg \& Leiche, 2008). 
Schooling is essentially a human endeavor. Students, teachers, administrators, staff, parents and others interact either face-to-face, or through some kind of electronic or on-line venue. These human interactions are part of our everyday life, but should be facilitated responsibly. With all the interactions in school-based work, emotions can be triggered, typically cast in positive or negative terms. While many terms are often used regarding emotions, Dasborough, Sinclair, Russell-Bennet and Tombs (2008) pointed out that the terms emotion, affect, mood and feelings are often used inter-changeably, when in fact, they are quite distinct. For example, emotions are seen as short in duration and related to a specific stimulus or behavior, while moods tend to last longer and are more diffuse often occurring for unknown reasons (Ashkanasy \& Dorris, 2017; Izzard, 1993).

Researchers have suggested that since these feelings and emotions ae inevitable through the interactions at work, they impact people and organizations. Humphrey, Burch and Adams (2016, p. 2) posited eight concepts regarding emotions and the workplace:

1. Emotions are present in the workplace

2. Employees may experience these events outside of work and bring them to the workplace

3. Other employees (including leaders) can trigger emotional events during the day

4. Events that occur during the workday or are relived through memories while at work will create emotions

5. These emotions must be dealt with, either through self-regulation or emotional labor

6. Emotions may be transferred to other employees

7. Leaders are susceptible to these same events

8. Leaders are capable of influencing the emotions and moods of their followers (both positively and negatively)

Multiple definitions for emotions exist (Ashkansay \& Dorris, 2017), with Kleinginna \& Kleinginna (1981) identifying over 92 in the literature. Fisher et al. (1990), in a commonly cited definition, offered that emotions are, a "discrete, innate, functional, biosocial action and expression system" (p. 84). Salovey \& Mayer (1990) simplified the definition, explaining that emotions are, "typically arising in response to an event, either internal or external, which has a positively or negatively valenced meaning for the individual" (p. 186). Plutchik (1980) set out eight primary emotions - joy, acceptance, fear, pride, sadness, disgust, anger, and anticipation. Ekman $(2003,1999)$ focused on the physiology and expression of emotions and sought to identify basic emotions. Indeed, Basch \& Fisher (2000) studied organizational settings, arguing that employees exhibit an array of emotions at work. Positive emotions most common were pleasure, happiness, pride, enthusiasm, relief, optimism, affection, and power. Typical negative work-related emotions included frustration, worry, disappointment, annoyance, anger, unhappiness, embarrassment, sadness, disgust, hurt, fear, and bitterness.

Given the wide range of human emotions inherent in any work setting, the concept of emotional contagion highlights the importance of understanding emotions. Simply put, an individual's emotions are easily conveyed and can impact others. As Pugh (2002) suggested, "through our interactions with others, we catch their emotions" (p. 161). Research has shown that leaders' emotions impact those they work with because it affects their leadership style (Hatfield et al., 1994; Cherulnik et al., 2001; Gross \& John 1997, Pugh, 2002). Goleman et al. (2002) summed it up as follows, "Everyone watches the boss: People take their emotional cues from the top" (p. 8).

Hochschild's (1983) landmark study, The Managed Heart, provided greater insight into the effects of emotions at work. Emotional work is the effort people put into keeping their primary feelings at bay or presented appropriately. Emotional labor is displaying the right face, the "organizational mask," that fits with the particular work setting. Employees are left to suppress their true feelings, surface act (superficial behavior) or deep act (modify feelings and emotions to fit the expected ways to behave) (Hochschild, 1983; Grandey, 2000). This work and labor can have profound consequences, including job-related behaviors, physical and psychological well-being, and withdrawal behaviors (Rubin et al., 2005).

The concept of emotional intelligence (EI) was first introduced by Salovey and Mayer (1990). They defined it as involving, "the ability to perceive accurately, appraise, and express emotion; the ability to assess and/or generate feelings when they facilitate thought; the ability to understand emotion and emotional knowledge; and the ability to regulate emotions to promote emotional and intellectual growth (Mayer \& Salovey, 1997, p. 10). Mainly introduced by Goleman (1995), who argued that it is more important than IQ for success at work, research and popular media focusing on emotional intelligence emerged covering so many traits and domains that Mayer, Salovey \& Caruso (2008) argued, "it is employed to cover too many things - too many traits; too many different topics" (p. 1). Instead, they focused the concept more and suggested that, "individuals high in EI pay attention to, use, understand, and manage feelings, and these skills serve adaptive functions that potentially benefit themselves and others" (p. 1). 
Today, with the strong focus on the importance of non-cognitive skills for success in any field, EI is widely recognized as key for leadership success. Caruso and Salovey's (2004), The Emotionally Intelligent Manager, set out an array of skills that people can have to understand emotions - make correct assumptions about people, know the right thing to say, make good predictions about what people feel, have a rich emotional vocabulary, understand that people can feel conflicting emotions, and have sophisticated emotional knowledge. Obviously, those that struggle with these are hampered in working with others. Mayer, Salovey \& Caruso (2008) evolved their work on EI to consider it on a continuum, from lower-level to more developmentally complex functions. This "four-branch" model begins at the lowest level with perceiving emotions in oneself and others, to using emotions to facilitate thinking, to understanding emotions, emotional language and the signals conveyed by emotions, and finally, to managing emotions so as to attain specific goals. These resonate closely with the more popularized components of EI set out by Goleman, Boyatzis and McKee (2002) - what is referred to as Personal competence incudes: (1) self-awareness and (2) self-management; and what is labeled Social competence encompasses: (3) social awareness and (4) relational management skills.

In school settings, the component concepts of emotional intelligence have taken hold in terms of the push for socio-emotional learning for students (SEL). The Collaborative for Academic, Social, and Emotional Learning (CASEL) is an organization many school districts rely on for information regarding SEL. It describes itself as a, "trusted source for knowledge about high-quality, evidence-based social and emotional learning (SEL). CASEL supports educators and policy leaders and enhances the experiences and outcomes for all PreK-12 students" (About CASEL, n.d.). CASEL defines SEL as follows:

"...the process through which children and adults understand and manage emotions, set and achieve positive goals, feel and show empathy for others, establish and maintain positive relationships, and make responsible decisions" (SEL is, n.d.).

The CASEL framework includes five core competencies (SEL: What are the core competence areas and where are they promoted?, n.d.):

Self-awareness: The ability to accurately recognize one's emotions and thoughts and their influence on behavior. This includes accurately assessing one's strengths and limitations and possessing a wellgrounded sense of confidence and optimism.

Self-management: The ability to regulate one's emotions, thoughts, and behaviors effectively in different situations. This includes managing stress, controlling impulses, motivating oneself, and setting and working toward achieving personal and academic goals.

Social awareness: The ability to take the perspective of and empathize with others from diverse backgrounds and cultures, to understand social and ethical norms for behavior, and to recognize family, school, and community resources and supports.

Relationship skills: The ability to establish and maintain healthy and rewarding relationships with diverse individuals and groups. This includes communicating clearly, listening actively, cooperating, resisting inappropriate social pressure, negotiating conflict constructively, and seeking and offering help when needed.

Responsible decision-making: The ability to make constructive and respectful choices about personal behavior and social interactions based on consideration of ethical standards, safety concerns, social norms, the realistic evaluation of consequences of various actions, and the well-being of self and others.

These competencies are directly drawn from and expand the work on EI, essentially mirroring the components of EI with the addition of the responsible decision-making component. CASEL works with individual school districts and states on implementing SEL strategies across the U.S., leading initiatives and providing resources to implement SEL practices and support policy development.

Research has examined the impact of SEL on a variety of student outcomes. An early meta-analysis (Durlak et al., 2011) focusing on 213 SEL programs involving over 273,000 Kindergarten through high school students found that SEL participants displayed improved SEL skills, attitudes, behaviors and academic performance. Specifically, performance improved 11 percentile points in achievement. A later meta-analysis Taylor et al. (2017) involving 82 school-based interventions with over 97,000 K-12 students focused on follow-up outcomes. These outcomes were collected from six months to 18 years after the intervention. Five positive youth development conclusions were drawn. There was durability of impact on seven outcomes - relationships, school status (e.g. attendance), sexuality behaviors, income, employment, criminality, and mental health. These impacts affected both positive and negative indicators of well-being, transcended all demographic groups studied, resulted in higher levels of well-being at follow-up, and impacted multiple other developmental outcomes such as graduation rates and safe sex behavior.

The need for SEL was recognized well before the pandemic emerged, with states in the U.S. like Kansas adopting SEL standards for all schools (Kansas Social, Emotional and Character Development 
Model Standards, revised July, 2018). The COVID19 pandemic, however, has exacerbated calls for strengthening SEL teaching and learning. A survey conducted by Center for Promise at America's Promise Alliance (Margolius et al., 2020) surveyed 3,300 teenagers in late April and May and found that significant segments of teenagers struggled with unhappiness, depression and anxiety during the school closures in spring 2020. They found that 40\% of youth weren't offered any social or emotional support by an adult in their school. The report concluded, "The survey findings point to a greater need for social and emotional support" (p. 5). Also this spring, a 2020 survey from the Rand American Educator Panels (Hamilton, Kaufman \& Dilberti, 2020) found that $23.2 \%$ of elementary and $24.8 \%$ of secondary principals identified high quality materials to support social and emotional learning as a major or very major need while buildings are closed. In the same survey, $21.3 \%$ of teachers identified SEL strategies or lesson plans as a major or very major need. A blog for the Learning Policy Institute (Schulund \& Weisberg, May 19, 2020) reported, "The pandemic has further illuminated the need for SEL to care for ourselves, our students, and their families" (p. 1). Finally, a survey of teachers by Educators for Excellence (2020) found that $69 \%$ of teachers reported that students expressed social concerns, with $62 \%$ having expressed emotional concerns.

Emotions affect a variety of variables in the work place which can have distinct impacts on performance. The growing literature on emotional intelligence highlights an array of factors that support individual and organizational success. Schools have embraced these through the curricular and instructional demands related to SEL. SEL is directed at helping individuals deal with the emotional factors affecting their world. The next section of the paper turns to discussing the key emotional triggers for those involved with schools.

\section{Emotional Triggers in Schools}

While the research on emotions clearly highlighted their impact on all aspects of human interactions, the triggers in schools tend to cluster around certain kinds of common behaviors connected to school-based work. To better understand these processes, ideas were gleaned from research on emotions and stress in schools (e.g. see, Ginsberg \& Davies, 2007; Ginsberg \& Multon, 2011a, 2011b) to establish a typology of the most common triggers. These lists were further developed based on informal discussions with multiple groups of practicing educators (teachers and administrators) in both Kansas and British Columbia, all of whom were being impacted by the current pandemic. While these weren't formal data collection processes, the resulting ideas from the research were shared, results compiled, then several panels of educational experts reviewed the typology to determine if the ideas presented captured the kinds of behaviors and interactions that trigger emotions for those involved with schools. While not scientifically verified, this early synopsis of emotional triggers for educators is represented in Table 1 . The data on the table does not differentiate the triggers impacted by student age, grade level, subject taught, years of professional experience for educators, or type of teaching or administrative role. It also doesn't capture emotional triggers for non-instructional staff. The data are drawn largely from U.S. with some Canadian input and review, but not from other countries around the world. While it is assumed these triggers are universal, these data need verification to be generalized.

Table 1. Emotional triggers for individuals associated with North American schools

\begin{tabular}{cccc}
\hline Issues & Students & Teachers/Instructional Staff & Administrators \\
\hline Behavioral & $\mathrm{X}$ & $\mathrm{X}$ & $\mathrm{X}$ \\
Social & $\mathrm{X}$ & $\mathrm{X}$ & $\mathrm{X}$ \\
Media/Technology & & $\mathrm{X}$ & $\mathrm{X}$ \\
Performance/Outcomes & $\mathrm{X}$ & $\mathrm{X}$ & $\mathrm{X}$ \\
Instruction/Teaching & $\mathrm{X}$ & $\mathrm{X}$ & $\mathrm{X}$ \\
Parents & $\mathrm{X}$ & $\mathrm{X}$ & $\mathrm{X}$ \\
Curriculum & & $\mathrm{X}$ & $\mathrm{X}$ \\
Job & & $\mathrm{X}$ & $\mathrm{X}$ \\
Readiness/Satisfaction & & & $\mathrm{X}$ \\
Leadership Decisions & & & \\
(personnel/budget) & & & \\
Community & & & \\
Pressure/School Board & & & \\
\hline
\end{tabular}


One of the significant emergent findings is that for all those engaged in schools, there are a plethora of issues and interactions that can spark emotional reactions. Certainly, there may be a great deal of interaction among the issues identified - e.g. a social media posting might ignite emotionally-laden feedback from parents to teachers. In terms of the identified issues, several, like behavioral issues, affects all those involved. School bullying, for example, an issue that has always plagued schools, impacts victims, bullies, bystanders, and all those empowered to address the issues in schools (Willford, et al., 2019) including students, teachers and administrators. Much the same in terms of widespread impact can be said about the growing use of social media and all forms of technology, sparked a good bit by the closing of schools and massive move to online instruction as a result of Covid-19. All those associated with schools carry concerns regarding student performance and teaching. And parents may not only bring pressure on their children, but on school officials as well. So many of the listed issues impact all the players in school settings.

Some issues however, are more directly experienced by the professionals within schools. Certainly, curricular issues might evoke emotional responses from all segments of society (e.g. sex education, more recently curricula regarding equity and racism), however these issues are typically the province of teachers and administrators to develop and implement. Job readiness (or the lack thereof) is perhaps best exemplified by the concerns being raised and dealt with regarding preparedness for online instruction during the pandemic. Since Covid-19 emerged last March, the lack of professional development for instructors and the lack of direction from administrators as to how best to proceed have been common complaints. Leadership decisions with the most emotional impact are typically in areas related to budget and personnel (Ginsberg \& Davies, 2007), but even budget and personnel decisions might also impact teachers. Community and school board pressure may affect broad numbers of individuals, but it is school administrators who are most directly involved with such concerns.

What is clear in the present climate Covid-19 impacted climate is that certain triggers have emerged as more potent than those typically affecting school educators and students. Multiple surveys have examined teachers, administrators and students responses to the pandemic (see, e.g. Berry et al, July, 2020; Bonella et al., 2020; Farrace, July 21, 2020; Hamilton et al., 2020; Kraft \& Simon, 2020; Educators for Excellence, 2020). For example, Berry et al. (2020) surveyed 12,000 South Carolina teachers (about 25\% of the South Carolina teaching workforce) and conducted 75 focus groups to understand the impact of the pandemic. Among the key findings, teachers reported experiencing stress related to students' adjustments to remote learning, and the many barriers they faced reaching students. Similarly, Bonella et al. (2020) surveyed over 800 Kansas teachers, reporting that over three quarters worried about the social-emotional well-being of students, along with similar worries about student access and engagement. Educators for Excellence conducted a representative U.S. national sample of 600 teachers posing 72 questions. Key results highlighted teacher concerns about student access and equity, low student engagement, their own ability to balance work with child care, with $87 \%$ indicating a very or somewhat serious challenge of staying focused on teaching and learning during the pandemic.

All the survey results and the aforementioned discussions with practitioners suggest that there are several common themes affecting those working in the education world in the current Covid-19 tempered situation. These include:

- Gnawing uncertainty - safety issues, financial impact worries (e.g. job security), and technology needs in terms of hardware, software and professional development,

- Rapidity of change and circumstance - Schools were closed very quickly last spring with little warning. No matter the mode of instruction offered with schools reopening, the possibility for switching again is powerful and disruptive

- Exacerbation of equity concerns - large percentages of students were hard to reach, while others didn't have access to appropriate hardware or Wi-Fi connections. This differentially impacts low SES students and many students of color

- Health fears - the easy spread of the virus is a driving factor, especially when teachers and students are forced into face-to-face teaching situations.

- Personal exhaustion - Educators in many of the survey results and comments discussed the emotional exhaustion many felt, what might be considered "pandemic overload" pervading school culture. With this, anxiety about when schools might return to pre-Covid teaching and learning "normalcy" is rampant.

- Work/Life balance - Online instruction is labor intensive, and many struggle with being forced to be at home with school-aged children who need their support and guidance academically.

- Unknowns related to effects on students - significant worries raised by educators on nearly every survey included the loss of learning, impact of moving remotely, and ability to catch up. 
While this list of emotional triggers may not be exhaustive, it is clear that the pandemic has raised the level of anxiety and emotional uncertainty impacting all those situated in or associated with schools.

\section{Emotions and Leadership}

For many decades, researchers studying organizations and leadership rarely examined emotions. Grandey (2000) argued that the prevalent sense was that emotions can cloud sound judgement and aren't helpful in understanding what happens in the workplace. They were, as Ashforth and Humphrey (1995) explained, "the antithesis of rationality" (p. 98). The past few decades witnessed much growth in examining emotions in the workplace, with the work on EI a central driver for this attention. As Berkovich \& Eyal (2015) described it regarding the shift in focus, emotions were recognized as, "a key psychological aspect in determining cognitions, motivations, and behaviors" (p. 129). But even with the growing focus on emotions in schools driven by EI and SEL, much of the literature continues to emphasize using and controlling emotions to improve performance and outcomes. These are laudable goals. Berkovich \& Eyal's (2015) review of 49 empirical studies focusing on research on educational leaders and emotions argued that emotions are central for understanding educational leaders in four ways. First, leaders have emotional experiences and their displays depict leaders' reactions to their surroundings and circumstances. Second, the behavior of those in leadership roles affects the emotions of those they interact with. Third, leaders' abilities in dealing with emotions and behaviors can impact work outcomes. Finally, leaders' emotions can be influenced by macro factors that create local and global turbulence. Certainly, the pandemic fits that category of influencing factors.

What is intriguing is that even with the shift to recognizing the importance of understanding emotions as they impact organizational behavior and leadership, the main thrust of most scholarship remains largely focused on using emotions to support performance and not on how the emotions take a toll on leaders. Peters and Austin (1985), for example, saw workplace feelings and emotions as necessary ingredients for organizational success. Ashforth \& Humphrey (1995) focused on what they called symbolic management, arguing that its success was dependent on the evocation of emotion. In their words, this form of leadership, "involves orchestrating, summarizing and elaborating symbols to evoke emotion which can be generalized to organizational ends" (p. 111). More recently, Berkovich \& Eyal's (2015) literature review concluded that "Educational organizations are increasingly being advised to select leaders who have high emotional abilities and to develop leadership behaviors that have positive emotional effects on followers in order to promote desired educational outcomes" (p. 158). Given that achieving outcomes is the reason organizations exist, this focus on educational outcomes makes sense. And some leadership studies do focus on the inner-side of this emotional push. Two of the key components of EI include self-awareness and self-management. Self-awareness is what it sounds like, the ability to understand one's inner signals and their impact. Self-management has multiple components, but includes a form of self-control to manage emotions, impulses and to perhaps direct them in appropriate and useful ways (Goleman et al., 2002). In Goleman et al.'s (2002) words, what they called resonant leaders, are emotionally intelligent leaders, who build resonance, "by tuning into people's feelings - their own and others' - and guiding them in the right direction" (p. 26).

The concept of self-regulation has emerged and permeated the organizational and leadership literature and captures the essence of these ideas of self-awareness, self-management and resonant leadership. Gross (1999) explained that emotional regulation involves three elements, influencing the types of emotions experienced, when they are experienced, and how they are displayed and experienced. According to Ashforth \& Humphrey (1995), only certain emotional expressions are acceptable in the work place, identifying four means for regulating work place emotions - neutralizing, buffering, prescribing, and normalizing. The concept of resiliency is also related to the EI competencies, a term with multiple definitions (Meredith et al, 2011). In the psychiatric world, it generally refers to positive adaptation or the ability to regain mental health after experiencing diversity (Herrmann, et al. 2011). Some definitions require positive growth following a stressful event, others just refer to adaptation (Britt et al., 2016). Britt et al. (2016) argued that, "Increased attention on resilience reflects a greater recognition among educators and employers that the development and retention of resilience must begin early, represents a lifelong activity, and is indispensable for educational and vocational success" (p. 388). In the current period, what some have referred to a time of VUCA (volatility, uncertainty, complexity and uncertainty), approaches like mindfulness have been suggested to strengthen leadership and positively impact organizational performance (Levey \& Levey, 2013; 2019). According to Carleton, Barling \& Trivionno (2018), current evidence suggests that trait mindfulness provides benefits for employee well-being, while Reb, Narayanan 
\& Chaturvedi (2014) found that leadership mindfulness was related to follower well-being and performance.

But even with the obvious appreciation of the impact of emotions on organizations and individuals, including leaders, the main thrust in the research on emotions and related leadership studies tends to be about controlling or harnessing personal impulses and emotions of leaders or employees in order to better attain the organizational goals. Consider the work on transformational leadership. First introduced in the 1980s (Bass, 1985, built on the work of Burns, 1978), transformational leadership is typically described as a leadership approach that inspires people to commit to an organization's vision and goals (Carleton, Barling \& Trivionno, 2018). It involves four dimensions - charisma or idealized influence, inspirational motivation, intellectual stimulation, and individualized consideration (Judge \& Piccolo, 2004; Banks et al., 2016). As Ashforth \& Humphrey (1995) described it, "By arousing emotion and harnessing it to the pursuit of lofty goals, transformational leadership represents a potentially potent force for change" (p. 117). Other recent theoretical approaches to leadership, such as authentic leadership (Banks et al., 2016; Walumbwa et al., 2008), tie leadership to factors closely related to studies on EI, including its four key components - self-awareness, relational transparency, balanced processing, and an internalized moral perspective. But in all these leadership approaches directly dealing with aspects of emotions and EI, the focus remains on leaders using emotions and emotional competencies to strive for organizational success. Never is the focus on how leaders are actually impacted by what they experience.

Concerns associated with the current pandemic are likely as visible a reason to better consider how emotions impact leaders than any event in recent history. Scholars have recognized the significance of understanding leadership in periods of crisis. There is research on crisis management, cutback management, and the directions for leaders to best handle such situations. But whether there is a crisis or not, leaders are impacted in multiple ways by the demands of their position. Note, for example, the work by Ginsberg \& Davies (2007), who interviewed educational and business leaders and found that personnel and financial decisions were the dominating issues causing emotional concerns for leaders, and they referred to the human toll this had as, "the agony of decision-making" (p. 39). Especially concerning for leaders was dealing with difficult employees, and in some cases, friends in the organization. In follow-up work during the recession with principals and superintendents (Ginsberg \& Multon, 2011a, 2011b), principals identified that they were concerned with doing more with less, that cuts were impacting students and teachers, that employees and others leveled intense anger at them (what was called "tornadoes of negativity'), and they were concerned about both their employee and personal levels of stress. For superintendents, they reported concerns about living in survival mode, disappointment in how people responded to the fiscal woes, loss of their joy for the job, and the difficulty in having to wear a happy face. What is clear is that at any time, leadership is challenging and can take an emotional toll. Leadership studies and theories need go beyond analyzing how emotions can be used to improve organizational importance. For leaders to thrive, dealing with the effects of the emotional burdens is equally significant.

\section{A Framework for Becoming an Emotionally Adaptable Leader (EAL)}

Given the emotional space school leaders populate, and the reality that nobody could have predicted the enormous impact of the current pandemic on schools, navigating these realities of leadership work is more important than perhaps ever before. Multiple areas associated with leadership theory and practice provide direction for developing a framework for the emotional side of leadership work. Specifically, elements of the studies on emotional intelligence and leadership, transformational leadership, resiliency in leadership and several associated constructs including hardiness, grit, mindfulness, and authentic leadership, Complexity Leadership, Leadership Wisdom, Crisis and Cutback Management, and emerging work on leadership tied to increasing performance - including collective Leadership and Uplifting Leadership - are examined and integrated to provide a beginning point for better understanding this significant element of leadership work and developing a framework for becoming an EAL.

Emotional Intelligence - While work on emotional intelligence fortified the significance of emotional understanding, much research on leadership had earlier underscored that it is basically about emotion management, both for leaders and followers (Yukl, 2002, Humphrey, 2008; van Knippengerg \& Van Kleef, 2016). Clearly, however, following the introduction of emotional intelligence in the early 1990's (Mayer \& Salovey, 1993), the idea of the importance of emotional intelligence for leaders took hold. Cooper \& Sawaf (1996) called emotional intelligence the driving force of twenty-first century business. Caruso and Salovey (2004) offered skills and planning ideas for emotionally intelligent managers. For Goleman, Boyatsis \& McKee (2002), emotional intelligence qualities are the driving force for successful leadership. 
In their words, "In the modern organization, the primordial emotional task - though by now largely invisible - remains foremost among the jobs of leadership: driving the collective emotions in a positive direction and clearing the smog created by toxic emotions" (p. 5). Leaders attuned to employees feelings, what they termed resonant leaders, both amplify and prolong the emotional impact of leadership. In another study, Goleman (1998a) was even more enthusiastic about the power of emotional intelligence where he argued that his comparisons of star leaders with others found that nearly $90 \%$ of their differences were attributable to emotional intelligence characteristics and not cognitive abilities. Indeed, Gardner \& Stough (2002) cited multiple studies in suggesting it is thought that emotionally intelligent leaders were happier and more committed to their organization, more successful, performed better, used positive emotions to bolster organizational functioning, and used emotions to strengthen their decisionmaking.

Literally hundreds of studies in the last twenty years have examined emotional intelligence for leadership in multiple fields as diverse as medical education (Mintz \& Stoller, 2014), nursing (VitelloCicciu, 2003), libraries (Krietz, 2009), family businesses (Boyatziz \& Soler, 2012), banking (Tsai, Tsai \& Wang, 2011), and construction project management (Sunindijo, Hadiksumo \& Ogunlana, 2007). The exact relationship between EI and leader effectiveness, however, remains in question (Walter, et al., 2011), with concerns raised about the self-report nature of the data for many studies. Recent research, however, shows promising results regarding the relationship of EI to leader effectiveness (Edelman \& van Knippenberg, 2018). But the inner side of emotional strain on leaders is only touched upon in all this work.

Transformational Leadership - The most dominant leadership theory of the past several decades is transformational leadership. It is defined as a form of leadership that involves inspiring others to the organization's vision and goals. It involves challenging followers to be innovative and be leaders themselves, through coaching, mentoring, challenge and support (Bass \& Riggio, 2006). Transformational leadership consists of four dimensions - charismatic or idealized influence, inspirational motivation, intellectual stimulation, and individualized consideration (Judge \& Piccolo, 2004). Studies have shown it to be effective on impacting employee performance and multiple other outcomes (Judge \& Piccolo, 2004; Farahnak et al., 2020). While transformational leadership encompasses several emotional elements related to leader behavior, including appealing to followers at an emotional level, inspiring them to act, and considering follower's needs, much as with EI, these behaviors are directed at developing others and not necessarily on leaders own emotional needs.

Resiliency and related concepts - Resiliency in leadership is more self-oriented and is related to a number of concepts evident in psychological and leadership studies, including resilience, hardiness, grit, mindfulness, and authentic leadership. Notably, Teo, Lee \& Lim (2017) argued that, "the survival of an organization during crisis is dependent on resilience of its members as well as its leadership" (p. 136). Resilience is a psychological term that has been studied since the 1970s. Stoddard's (2020) examination of resilience found that definitions include concepts like bouncing back from adversity, returning to a former shape after being pulled or bent, or rising when you fall. He concluded that all the definitions suggest a cycle, "wherein an individual possesses and demonstrates the ability to face an adversity, to process and react to that adversity, and to emerge with a new homeostatic state after regaining stability or normalization" (p. 142). Patterson et al. (2009) suggested three sets of skills that resilient leaders possess - resilient thinking, resilient capacity, and resilient action. In the nursing field, Stagman-Tryer (2014) offered a conceptual triad for resilience - equanimity (a sense of calmness or even-temperedness), optimism (being positive), and perseverance (ability to press forward). Writing about successful superintendents, Fullan (2005) called for resiliency and sustainability, mapping out eight elements of sustainability for those wanting to make a difference.

The term hardiness has been described as a pathway to resilience. Maddi (2006) described how it has been conceptualized as involving the 3 C's - commitment, control, and challenge. It requires being involved with employees, having an influence on outcomes, and accepting stress as part of normal living providing opportunities for growth and learning. Kobasa (1979) argued that hardiness is linked to ongoing health and performance in stressful situations. Grit is a related non-cognitive variable associated with success. Grit, in its simplest terms, is perseverance, and includes a passion for obtaining longer term goals (Duckworth, et al., 2007). It is predictive of success in multiple areas, involving the ability to stickto-it in overcoming obstacles over time in the pursuit if goals. Mindfulness, is also tied to leader resilience (Levey \& Levey, 2019). Dane (2011) explained that mindfulness is a state of consciousness in humans that can be assessed at the trait level. Attention is focused on the present, and it occurs both in the environment and internally. Simply put, it is, "a mental state achieved by focusing one's awareness on the present moment, while calmly acknowledging and nonjudgmentally accepting feelings and thoughts" (Sanyal \& Rigg, 2020, p. 2). While much of the research on it is theoretical in nature, there are studies 
linking it to positive leadership outcomes including mental health (Roche et al., 2014), employee wellbeing, effectiveness (Reb et al., 2014) and leader flexibility (Baron et. al. 2017).

An emerging leadership approach called authentic leadership is also associated with resiliency. It involves self-awareness, relational transparency, balanced treatment of information, and an internalized moral perspective (Walumbwa et al, 2008; Baron, 2016). Simply put, authentic leaders have real relations with their workers and colleagues that are characterized by transparency, openness, and trust, driven towards identified objectives, with a focus on developing similar traits in their colleagues (Gardner, et al. 2005). Studies suggest it relates to multiple positive behaviors of workers and organizations (Walumbwa et al., 2008; Lee, 2018). Specifically, for purposes here, as described by Gardner et al. (2005), authentic leaders, "draw from the positive psychological states that accompany optimal self-esteem and psychological well-being, such as confidence, optimism, hope and resilience, to model and promote development of these states in others" (p. 345). They know themselves and portray who they are with others.

All these concepts share notions of individuals and leaders who understand their personal emotional issues and struggles. This understanding is directed at improving leadership or related behavior that allow individuals to be successful in their work and organizational responsibilities. But they don't directly address how leaders and others whose positions evoke such responses can actively deal with them. In other words, you might be resilient, but how are you to be prepared to deal with the emotional weight of your position and consider ways to cope and thrive?

Complexity Leadership - Wheatley (1992) brought consideration of complexity science to the world of leadership. Built primarily upon work in quantum physics (and areas in chemistry, mathematics, and biology), which recognized that the familiar mechanistic, linear and predictable views of systems was wrong, complexity science instead suggested that open systems are characterized more by being nonlinear, unpredictable and uncertain.

Holland (1995), originally described complex adaptive systems as having six components. There are many agents or units acting in parallel, whose interactions shape the system. Second, there are few controls over these interactions. Third, there are multiple levels of interactions and organization, with building blocks for higher levels. Fourth, as systems gain experience, these building blocks constantly are revised, what some refer to as adaptation. Next, Holland (1995) referred to what he called schemata, internal models that exist for how systems operate. Finally, there is constant, and ongoing novelty creating multiple niches, with some being filled by the agents within the system. Uhl-Bien, Marion \& McKelvey (2007), described these systems as follows:

Complex adaptive systems (CAS) are a basic unit of analysis in complexity science. CAS are neural-like networks of interacting, interdependent agents who are bonded in a cooperative dynamic by common goal, outlook, need, etc. They are changeable structures with multiple, overlapping hierarchies, and like the individuals that comprise them, CAS are linked with one another in a dynamic, interactive network (p. 299).

Wheatley (1992) suggested that the new science of complexity implies that leadership needs to move away from the language of design, regularity and control, and instead become more fluid, enabling and adaptive (Stacey et al., 2000; Uhl-Bien \& Marion, 2011). Wheatley (1992) specifically argued for participatory approaches, focusing on relationships and teams, allowing for the free generation and exchange of ideas, and promoting autonomy and greater self-reference. Similarly, Stacey (1995) called for accepting even embracing uncertainty, being open-ended, accepting surprise given that all answers aren't knowable. For Clarke (2013), this meant that complexity leadership focuses on, "trying to capitalize on these interactive dynamics and fostering the interactive conditions through which productive outcomes become more, rather than less, likely" (p. 138). As Uhl-Bien \& Marion (2011) summarized, "the field of leadership is in the midst of a paradigm shift, in which traditional models are giving way to new conceptualizations of leadership and organizing" (p. 468).

This emerging approach to understanding leadership has significant implications for the emotional whirl leaders confront. When control doesn't work, and uncertainty prevails, the likelihood for internal emotional strain is heightened. It is the acceptance and ability to navigate the flow of emotions that seems crucial in this context.

Wisdom - in light of the pandemic and the multiple challenges facing leaders, the Center for Practical Wisdom recently set forth the notion of what they refer to as "The Pillars of Leadership Wisdom" (Ellis, July 6, 2020). These four pillars relate closely with elements of EI, resilience, and various components of other leadership theories and approaches. Their notions of wise leaders include developing and applying an effective perception of reality. This includes being cognizant of your own biases and distortions. Next, wise leaders create conditions for workers to do their best. This includes strong communication, transparency and sharing ideas. Third, wise leaders shape a climate of trust through personal integrity. 
Trust is a key component of other leadership approaches (e.g. Hargreaves et al., 2014), and involves good faith, being candid and honest. The final pillar is personifying what is called, "positive equanimity." This involves being steady, willing to learn and serve, and avoiding the kinds of gut reactions and outbursts that can cause strain.

While this notion of wise leadership isn't a formal leadership theory, it offers a practical approach built on years of study from a formidable center at the University of Chicago. But it also speaks to the need for leaders to have a grasp of their emotions in dealing with the strains inherent in the work.

Crisis and Cutback Management - Crises are inevitable, and research has built strong models of crisis management. Pearson \& Clair (1998) defined an organizational crisis as, "a low probability, high-impact event that threatens the viability of the organization and is characterized by ambiguity of cause, effect, and means of resolution, as well as by a belief that decisions must be made swiftly" (p. 60. ). Indeed, they identified 27 types of organizational crises (see, also Miller, 2006). James \& Wooten (2005) argued that the consequences of mishandling a crisis can linger for decades. They emphasize that is it the handling or mishandling of the crisis - not the crisis itself - that can have the greater consequences. They further clarified that crises can be sudden (unexpected) or smoldering (events that evolve over time). Coombs (2007) argued that a crisis can have three threats to an organization - public safety, financial loss, and reputation. Indeed, an entire literature on what has been described as cutback leadership and management evolved during multiple prior recessions (Levine, 1978, 1979; Biller, 1980; Brombyk \& Chernesky (1985). Much of the focus of all these studies includes maintaining staff morale (Behn, 1980). And a variety of models for leaders have been developed for handling crises (e.g. Coombs, 2007, James \& Wooten, 2005; Smits \& Ally, 2003; Teo, Lee \& Lim, 2017).

In the education space, (Ginsberg \& Multon, 2011, 2011a) studied K-12 leaders responses to the financial stresses of the 2008 recession. Their focus was specifically on how the school leaders were affected when dealing with significant budget challenges. These studies were unique in the crisis management literature by moving away from focusing on definitions, organizational impact and strategy, to considering the specific effects on leaders and how they responded to the emotional strain of confronting fiscal - and ostensibly - other types of emotionally-laden work challenges.

Uplifting and Collective Leadership - Many new approaches to leadership are developing in the education space (Eckert, 2019). Most focus on the kinds of leadership processes needed to bolster performance in schools and other fields. Hargreaves et al. (2014), for example, called for uplifting leadership, studying 15 organizations in education, business and sports over a seven year period. The model has six distinct components, based on the assumption that, "emotional and spiritual uplift is the beating heart of effective leadership" (p. 3). The model encompasses the ideas of dreaming with determination, creativity and counter-flow, collaboration with competition, pushing and pulling the group, measuring with meaning, and focusing on sustainable success. In their words, uplifting leadership requires both inspiration and dogged determination.

A related model, what Eckert (2019) calls collective leadership, focuses on combining both teacher and administrator leadership in joint goal setting and strategic implementation towards the natural goals of improving teaching and learning. The model leads to greater relational trust and professional capital in the school organization. Collective leadership shares many goals with other models, focusing on trust and collective work aimed at clear goals. For leaders to thrive in any such model, they need to stay attentive and manage controlling their impulses, while in striving reach towards and find a common ground on what is good for everyone. This is where the idea of becoming an emotionally adaptive leader takes hold.

Summary: The Case for Becoming an Emotionally Adaptive Leader - Analyzing the multiple areas of scholarship related to leadership provides a basis for conceptualizing a simple element for any leadership approach to work. Given that the work is hard, that decisions have consequences, and that the flow of unanticipated challenges is a regular component of being in charge, a better means for capturing the potential emotional consequences of these realities is significant for leadership success. Being an emotionally adaptive leader is important. After all, leaders are just people, whose ability to perform is impacted by the strains that flow through the workplace. Emotions are powerful, and while being happy can be a tonic to lift one up, fear can be damning and toxic (Robin, 2004). Put simply, leaders are human, they make mistakes, they have good and bad traits. At times, they disappoint us, even becoming nasty and capricious (Maddock \& Fulton, 1998). As Bardaraco (1997) explained it, if Hitler could sometimes sleep well while Mother Teresa had sleepless nights, the simple notion that doing good or right doesn't capture how emotions may have an impact on everyone.

Common themes emerge for the array of different studies reviewed. Together, they suggest that for leaders to thrive, they will need to be adaptable to their emotional states and the elements in their work impacting them. While this ties with the notion of emotional awareness in the EI literature, it differs with a specific focus for leaders on understanding how elements of the job are affecting them. It isn't enough to 
just know yourself and be cognizant of others' emotional state, instead leaders need to know what their emotional triggers are, what parts of the work affects them, and learn ways to cope and sustain themselves. This side of emotional awareness isn't emphasized enough in any leadership studies or approaches. As several scholars studying emotions put it, "The leader is just another individual...they put their pants on just like the rest of us do" (Maddock \& Fulton, 1998, p. 15).

Twelve themes are drawn from the study of EI, resilience and related concepts, complexity leadership, wise leadership, crisis management, and emerging approaches to leadership success. Together, they capture what is being labeled as becoming an emotionally adaptable leader:

1. Embrace uncertainty - drawn from the complexity leadership literature, this involves releasing deeply held notions of control while concomitantly aggressively framing needs and possibilities. Uplifting leadership emphasized the need to dream and be creative. In an uncertain world, characterized by what complexity scientists refer to as adaptability and emergence, gaining comfort from uncertainty can potentially limit the emotional strain of working in a chaotic space.

2. Accept that leadership involves emotional experiences - This reality is the essence of EI as it relates to leadership. Research on emotions underscores the inevitability of emotional experiences at work. Leadership entails directing human experiences, making hard decisions, accepting responsibility for what happens. This has emotional consequences.

3. Learn to become flexible and adaptive - Resilient leaders understand this. It is the essence of what complexity leadership entails, that adaptability frames the future.

4. Know yourself and those you work with - EI has a strong focus on understanding your own and others emotions. It is a key starting point for leadership emotional adaptability.

5. Allow yourself to hope and dream - This is a key component of uplifting leadership. As Hargreaves et al., (2014) suggested, "your success is motivated by an inspiring dream" (p. 31). Authentic leadership, the work of wise leadership, and other leadership approaches solidify the concern with hope and optimism. Emotionally adaptable leadership demands this kind of thinking.

6. Understand that people and personal relations rule - While collective leadership is directly focused on relationships and personal interactions, nearly all the leadership theories contend that interactions with and among people are key for organizational and leader success. Fullan (2016) suggested that for change to be successful in schools, leaders must allow the group to change the group. Emotionally adaptable leaders recognize that operating in a vacuum will limit success and take personal toll.

7. Be a hardy soul - Hardiness, resilience, grit and mindfulness all speak to the idea of leaders facing adversity and being able to bounce back. It involves accepting the stress associated with the job and learning ways to deal with it.

8. Set a positive tone - Even in the most collaborative and collective models, the leader is identified as key for inspiring the atmosphere of the culture. This is part of the emotional work and labor Hochschild (1983) identified. EI for leadership is built on the belief that the leader sets the tone.

9. Promote shared values of trust and integrity -Being honest with yourself and your colleagues is important. Trust is identified as key for success by varying leadership approaches. And personally, the issue of integrity is healing, framed well by the great UCLA basketball coach John Wooden, who explained, "There is no pillow as soft as a clear conscience."

10. Take stock - demand corrective feedback - Hargreaves et al. (2014) called for measuring with meaning, using data that is meaningful, shared, and fair. Don't obsess about data, use them appropriately to guide you forward.

11. Be prepared - The work on crisis management was clear that having plans in place can help mitigate against the unforeseen. Similarly, Caruso and Salovey (2004) called for managers to develop an emotional blueprint or plan.

12. Learn patience - Wise leaders display what was termed positive equanimity. Learning to control emotions - emotional regulation - is important as long as leaders accept reality and don't completely stifle the difficult emotions they confront.

\section{Conclusions and Recommendations: Sustaining and Coping in Emotionally-Laden Episodes}

The argument developed here is that becoming an emotionally adaptable leader is significant for leaders to succeed no matter the specific approach to leading being employed. The pandemic certainly exacerbated many of the stressors and emotional feelings facing leaders in schools. But the reality is that leadership always has its emotional moments and periods, and learning to adapt to emotions and handle 
this difficult side of leadership work is important at any time. Research on emotions and varying leadership studies all imply the need for embracing an approach of being emotionally adaptable. As Levey and Levey (2019) put it, "if mindlessness persists, our stress accumulates, and we feel ever more overwhelmed and out of balance (p.739).

The idea of becoming an emotionally adaptable leader was drawn from the growing research in education and other fields that suggests that leadership is inundated with emotion invoking activity, along with studies that examined how work-related decisions and events take an emotional toll on leaders (Ginsberg \& Davies, 2017; Ginsberg \& Multon, 2011a: Ginsberg \& Multon, 2011b. The paper identified the kinds of work tasks and events that trigger emotions in schools, then drawing from an array of studies on emotional intelligence, resiliency and related concepts, transformational leadership, complexity leadership and wisdom, uplifting and collective leadership, and studies on crisis management, offered a framework and series of themes characterizing the concept of becoming an emotionally adaptable leader. While leaders always face enormous challenges and obstacles to achieving success, the onset of the pandemic, and the multiple unknowns and uncertainties it brought, make being emotionally adaptable more important than ever before. The stranglehold the pandemic has brought to school and community budgets, the uncertainties regarding student access and successful learning due to remote teaching, the challenges of using new forms of technology, and all the unknowns related to health, safety and work that COVID-19 ignited, together underscore the importance for school leaders to embrace emotionally adaptable leadership in the prevailing environment.

Developing useful coping strategies is the key for learning to deal with the emotions that strike. Drawn from prior work on emotional leadership (Ginsberg \& Davies, 2007, Ginsberg \& Multon, 2011, 2011a), along with elements from the research on emotions and data collected for the discussion of school-based emotional triggers, Appendix A offers coping strategies for leaders developing an emotionally adaptable orientation. The strategies are broken into two parts - short-term coping (ways to cope in real time on the job) and long-term thriving (ideas for developing skills and mindsets for coping in the future). While the distinction between coping and thriving may be blurred, understanding what leaders must do to account for and deal with their emotions is fundamental.

\section{*Acknowledgement}

This study was presented as a keynote speech at 5th International Conference on Lifelong Education and Leadership for All-ICLEL20 in Baku, Azerbaijan on July 16, 2020.

\section{References}

About Casel (n.d.). Retreived from https://casel.org/about-2/

Ashforth, B.E. \& Humphrey,R.H. (1995). Emotion in the workplace: A reappraisal. Human Relations, $48(2), 97-125$.

Ashkanasy, N.M. \& Dorris, A.D. (2017). Emotions in the workplace. Annual Review of Organizational Psychology and Organizational Behavior, 4, 67-90.

Badarocco, J.L., Jr. (1997). Defining moments: When managers must choose between right and right. Boston, MA: Harvard Business School Press.

Banks, G.C., McCauley, K.D., Gardner, W.L. \& Guler, C.E. (2016). A meta-analytic review of authentic and transformational leadership: A test for redundancy. The Leadership Quarterly, 27, 634-652.

Baron, L. (2016). Authentic leadership and mindfulness development through action learning. Journal of Management Psychology, 31(1), 296-311.

Baron, L., Rouleau, V., Gregoire, S. \& Baron, C. (2017). Mindfulness and leadership flexibility. Journal of Management Development, 37(2), 165-177.

Basch, J. \& Fischer, C.D. (2000). Affective events-emotions matrix: A classification of work events and associated emotions. In, N.M. Ashkanasy, Hartel, C.E.J., \& Zerbe, W., Emotions in the workplace: Research, theory, and practice, 36-48. Westport, CT: Quorum Books.

Bass, B.M. (1985). Leadership and performance beyond expectations. New York, NY: Free Press.

Bass, B.M. \& Riggio, R.E. (2006). Transformational Leadership, $2^{\text {nd }}$ edition. Mahwah, NJ: Lawrence Erlbaum.

Behn, R.D. (1980). Leadership for cut-back management. The use of corporate strategy. Public Administration Review, 40, 613-620.

Bellet, C.S., De Neve, J-E, \& Ward, G. (2020). Does employee happiness have an impact on productivity? The London School: Centre for Economic Performance. CEP Discussion Paper No. 1655. 
Berkovich, I. \& Eyal, O. (2015). Educational leaders and emotions: An international review of empirical evidence 1992-2012. Review of Educational Research, 85(1), 129-167.

Berry, B., Dickinson, T., Harrist, J., Pompey, K., Zheng, J., Irvin, M., Moon, A., \& Hodges, T. (July, 2020). Teachers and teaching in the midst of a pandemic: Implications for South Carolina's policy leaders. All4SC, College of Education, University of South Carolina, Columbia, SC.

Biller, R.P. (1980). Leadership tactics for retrenchment. Public Administration Review, 40, 605-609.

Bombyk, M.J. \& Chernesky, R.H. (1985). Conventional cutback leadership and the quality of the workplace: Is beta better? Administration in Social Work, 9, 47-56.

Bonella, L., Carroll, D., Jobe, M., Kaff, M., Lane, J., Martinez, T., McKeeman, L., \& Shuman, C. (2020). Access, engagement, and resilience during covid-19 remote learning. White Paper - Kansas State University, College of Education Research Group, Manhattan, KS.

Boyatzis, R.E. \& Soler, C. (2012). Vision, leadership and emotional intelligence transforming family business. Journal of Family Business Management, 2(1), 23-30.

Britt, T.W. Shen, W., Sinclair, R.R., Grossman, M.R. \& Klieger, D.M. (2016). How much do we really know about employee resilience? Industrial and Organizational Psychology, 9(2), 378-404.

Burns, J.M. (1978). Leadership. New York, NY: Harper and Row.

Carleton, E.L., Barling, J. \& Trivisonno, M. (2018). Leaders' trait mindfulness and transformational leadership: The mediating roles of leaders' positive affect and leadership efficacy. Canadian Journal of Behavioural Science, 50(3), 185-194.

Caruso, D.R. \& Salovey, P. (2004). The emotionally intelligent manager: How to develop and use the four key emotional skills of leadership. San Fancisco, CA: Jossey-Bass.

Cherulnik, P.D., Donley, K.A., Wiewel, T.S.R., \& Miller, S.R. (2001). Charisma is contagious: The effect of leaders' charisma on observers' affect. Journal of Applied Social Psychology, 31(10), 2149-2159.

Clarke, N. (2013). Model of complexity leadership development. Human Resource Development International, 16(2), 135-150.

Coombs, W.T. (2007). Crisis management and communication. Gainesville, FL: Institute for Public Relations Essential Knowledge Project.

Cooper, R.K. \& Sawaf, A. (1996). Executive EQ: Emotional intelligence in leadership \& organization. New York: Grossett/Putnam.

Dane, E. (2011). Paying attention to mindfulness and its effects on task performance in the workplace. Journal of Management, 37(4), 997-1018.

Dashborough, M.T., Sinclair, M., Russell-Bennett, R., Tombs, A, (2008). Measuring emotion: Methodological issues and alternatives. In Research Companion to Emotion in Organizations, N.M. Ashkanasy, C.L. Cooper, Eds. 197-208. Cheltenham, UK: Edward Elgar Publisher, Ltd.

Duckworth, A. L., Peterson, C., Matthews, M.D. \& Kelly, D.R. (2007). Journal of Personality and Social Psychology, 92(6), 1087-1101.

Durlak, J. A., Weissberg, R. P., Dymnicki, A. B., Taylor, R. D., \& Schellinger, K. B. (2011). The impact of enhancing students' social and emotional learning: A meta-analysis of school-based universal interventions. Child Development, 82, 405- 432. https://doi.org/10.1111/j.14678624.2010.01564.x

Eckert, J. (2019). Collective leadership development: Emerging themes from urban, suburban, and rural high schools. Educational Administration Quarterly, 55(3), 477-509.

Ekman, P. (2003). Emotions revealed: Recognizing faces and feelings to improve communication and emotional life. NY: Times Books (Henry Holt and Company).

Ekman, P. (1999). Basic emotions. In T. Dalgleish and M.J. Powers, Eds., Handbook of Cognition and Emotion, 45-60. Chichester: John Wiley and Sons.

Edelman, P. \& van Knippenberg, D. (2018). Emotional intelligence, management of subordinate's emotions, and leadership effectiveness. Leadership and Organization Development Journal, 39(5), 592-607.

Educators for Excellence (2020). Voices from the virtual classroom: A survey of America's teachers on covid-19-related education https://e4e.org/sites/default/files/voices_from_the_virtual_classroom_2020.pdf

Ellis, C. (July 6, 2020). The pillars of leadership wisdom. University of Chicago, Center for Practical Wisdom. https://wisdomcenter.uchicago.edu/news/discussions/pillars-leadership-wisdom

Farahnak, L.R., Ehrhart, M.G., Torrews, E.M. \& Aarons, G.A. (2020). Journal of Leadership and Organizational Studies, 27(1), 98-111.

Farrace, B. (August 21, 2020). Principal say pandemic conditions are accelerating their plans to leave the principalship. NASSP, School of Thought, Blog Post. 
https://blog.nassp.org/2020/08/21/principals-say-pandemic-conditions-are-accelerating-theirplans-to-leave-the-principalship/

Fischer, K.W., Shaver, P.D., \& Carnochan, P. (1990). How emotions develop and how they organize development. Cognitive Emotions, 4, 81-127.

Frijda, N. (1992). The empirical status of the laws of emotion. Cognition and Emotion, 6(6), 467-477.

Fullan, M. (February, 2016). Amplify change with professional capital. JSD, 37(1), 44-56.

Fullan, M. (2005). Resiliency and sustainability. The School Administrator, 62(2), 16-19.

Gardner, L. \& Stough, C. (2002). Leadership and Organizational Development Journal, 23(2), 68-78.

Gardner, W.L., Aviolo, B.J., Luthans, F., May, D.R. \& Walumbwa, F. (2005). Can you see the real me? A selfbased model of authentic leader and follower development. The Leadership Quarterly, 16, 343-372.

Ginsberg, R. \& Davies, T.G. (2007). The human side of leadership: Navigating emotions at work. Westport, CT: Preager.

Ginsberg, R. \& Lyche, L.F. (2008). The culture of fear and the politics of education. Educational Policy, 22 (1), 10-27.

Ginsberg R. \& Multon, K.D. (2011a). Leading in financially stressful times, 53-67. In, B.S. Cooper \& S. Conley, Eds., Keeping and Improving Today's School Leader's. NY: Rowman \& Littlefied

Ginsberg, R. \& Multon, K.D. (2011b). Leading through a fiscal nightmare: The impact on principals and superintendents. Kappan, 92(8), 42-47.

Glassner, B. (1999). The culture of fear: Why Americans are afraid of the wrong things. NY: Basic Books.

Goleman, D. (1995). Emotional intelligence: Why it can matter more than IQ.NY: Bantam Books.

Goleman, D. (1998a). What makes a leader? Harvard Business Review, 76(6), 93-101.

Goleman, D. (1998b). Working with emotional intelligence. New York: Bantam Books.

Goleman, D., Boyatzis, R., McKee, A. (2002). Primal Leadership. Boston, MA: Harvard Business School Press.

Grandey, A.A. (2000). Emotion regulation in the workplace: A new way to conceptualize emotional labor. Journal of Occupational Health Psychology, 5, 95-100.

Gross, J.J. (1999). Emotion regulation: Past, present, future. Cognition and Emotion, 13, 551-573.

Gross, J.J. \& John, O.P. (1997). Revealing feelings: Facets of emotional expressivity in self-reports, peer ratings, and behavior. Journal of Personality and Social Psychology, 72, 435-448.

Hamilton, L.S., Kaufman, J.H. \& Dilberti, M. (2020). Teaching and learning through a pandemic: Key findings from the American educator panels spring 2020 Covid-19 surveys. Rand Corp: The American Educator Panels. https://www.rand.org/pubs/research_reports/RRA168-2.html

Hamline, N., El Moujahid, O., \& Thaichon, P. (2017). Emotion and advertising effectiveness: A novel facial expression analysis approach. Journal of Retailing and Consumer Services, 36, 103-111.

Hargreaves, A., Boyle, A. \& Harris, A. (2014). Uplifting leadership: How organizations, teams, and communities raise performance. San Francisco, CA: Jossey-Bass.

Hatfield, E., Cacioppo, J. \& Rapson, R.L. (1994). Emotional contagion. New York, NY: Cambridge University Press.

Herrman, H., Stewart, D.E., Diaz-Granados, N., Berger, E.L., Jackson, B. \& Yuen, T. (2011). What is resilience? Canadian Journal of Psychiatry, 56(5), 258-265.

Hochschild, A. R. (1983). The managed heart: Commercialization of human feelings. Berkeley, CA: University of California Press.

Holland, J.H. (1995). Hidden order: How adaptation builds complexity. Reading, MA: Addison Wesley.

Humphrey, R.H., Burch, G.F., Adams, L.L. (2016). The benefits of merging leadership research with emotions research. Frontiers in Psychology, 7, Article 1022, 1-12.

Humphrey, R.H. (2008). The right way to lead with emotional labor. In Humphrey, R.H., Ed., Affect and Emotion: New Directions in Management Theory and Research, pp. 1-17. Charlotte, NC: Information Age.

Izzard, C.E. (1993). Four systems for emotion activation: cognitive and non-cognitive processes. Psychological Review, 100, 68-90.

James, E.H. \& Wooten, L.P. (2005). Leadership as (un)usual: How to display competence in times of crisis. Organizational Dynamics, 34(2), 141-152.

Judge, T.A. \& Piccolo, R.F. (2004). Transformational and transactional leadership: A meta-analytic test of their relative validity. Journal of Applied Psychology, 89(5), 755-768.

Kansas social, emotional, and character development model stadards (revised, July, 2018). Retreived from Microsoft Word - SECD Standards FINAL Approved Revision 7-18 (ksde.org)

Kleinginna, P.R. \& Kleinginna, A.M. (1981). A categorized list of emotion definitions, with suggestions for a consensual definition. Motivation and Emotion, 5(4), 345-379. 
Kobasa, S.C. (1979). Stressful life events, personality, and health: An inquiry into hardiness. Journal of Personality and Social Psychology, 37, 1-11.

Kraft, M.A. \& Simon, N.S. (June 24, 2020). School organizational practices and the challenges of remote teaching during a pandemic. Shanker Blog, Albert Shanker Institute. https://www.shankerinstitute.org/blog/school-organizational-practices-and-challenges-remoteteaching-during-pandemic

Krietz, P.A. (2009). Leadership and emotional intelligence: A study of university library directors and their senior management teams. College and Research Libraries, 70(6), 531-554. https://crl.acrl.org/index.php/crl/article/view/16043

Lee, C.S. (2018). Authentic leadership and organizational effectiveness: The roles of hope, grit, and growth mindset. International Journal of Pure and Applied mathematics. 118(19), 383-401,

Levey, J. \& Levey, M. (2019). Mindful leadership for personal and organizational resilience. Clinical Radiology, 74, 739-745.

Levey, J. \& Levey, M. (2013). Thriving in complex times. MWorld, 12(2) 34-37.

Levine, C.H. (1979). More on cutback management: Hard questions for hard times. Public Administration Review, 39, 179-183.

Levine, C.H. (1978). Organizational decline and cutback management. Public Administration Review, 38, 316-325.

Maddi, S. R. (2006). Hardiness: The courage to grow from stresses. The Journal of Positive Psychology, $1(3), 160-168$.

Maddock, R.C. \& Fulton, R.L. (1998). Motivation, emotions, and leadership. Westport, CT: Quorum Books.

Margolius, M., Doyle Lynch, A., Pufall Jones, E. \& Hynes, M. (2020). The State of Young People during COVID-19: Findings from a nationally representative survey of high school youth. Americas Promise Alliance.

Mayer, J.D. \& Salovey, P. (1997). What is emotional intelligence? In, Salovey, P. \& Sluyter, J.D., Eds., Emotional Development and Emotional Intelligence: Educational Implications. New York: Basic Books.

Mayer, J.D. \& Salovey, P. (1993). The intelligence of emotional intelligence. Intelligence, 17, 433-442.

Mayer, J.D., Salovey, P., \& Caruso, D.R. (2008). Emotional intelligence: New ability or eclectic traits? American Psychologist, 63, 503-517.

Meredith, S., Sherbourne, C., Gaillot, S.J., Hansell, L., Ritschard, H.V., Parker, A.M \& Wrenn, G. (2011). Promoting psychological resilience in the U.S. military. Santa Monica, CA: Rand Corporation.

Miller, D. (2006). Organizational pathology and industrial crisis. In D. Smith \& D. Elliott, Eds., Key readings in crisis management: Systems and structures for prevention and recovery, 75-83. London: Routlege, Taylor Francis Group.

Mintz,L.J. \& Stoller, J.K. (2014). A systematic review of physician leadership and emotional intelligence. Journal of Graduate Medical Education, 6(1), 21-31.

Mitroff, I.I., Diamond, M.A. \& Alpaslan, M.C. (2006). How prepared are America's colleges and universities for major crises? Change: The Magazine of Higher Learning, 38:1, 61-67, DOI: 10.3200/CHNG.38.1.61-67.

Patterson, J.L., Goens, G.A. \& Reed, D.E. (2009). Resilient leadership for turbulent times. Lanham, MD: Rowan \& Littlefield Education.

Pearson, C.H. \& Clair, J.A. (1998). Reframing crisis management. The Academy of Management Review, 23(1), 59-76.

Pekrun, R. \& Frese, M. (1992). Emotions in work and achievement. In, C.I. Cooper \& I.T. Robertson, Eds., International Review of Industrial and Organizational Psychology. Chichester, UK: Wiley.

Peters, T.J. \& Austin, N. (1985). A passion for excellence: The leadership difference. New York: Random House.

Plutchnik, R. (1980). A general psychoevolutionary theory of emotion, 3-33. In, R. Plutchnik \& H. Kellerman, Eds., Emotion: Theory, Research and Experience. San Diego: Academic Press.

Pugh, S.D. (2002). Emotional regulation in individuals and dyads. In, Klimoski, R.J., Kanfer, R., \& Lord, R.G., Eds', Emotions in the Workplace: Understanding the Structure and Role of Emotions in Organizational Behavior. San Francisco, CA: Jossey-Bass.

Rathore, D., Chadha, N.K. \& Rana, S. (2017). Emotional intelligence in the workplace. Indian Journal of Positive Psychology, 8(2), 161-165.

Reb, J., Narayanan, J. \& Chaturvedi, S. (2014). Leading mindfully: Two studies on the influence of supervisor trait mindfulness on employee well-being and performance. Mindfulness, 5(1), 36-45.

Reiff, H. B., Gerber, P.J. \& Ginsberg, R. (1997). Exceeding expectations. Austin, TX: Pro-Ed. 
Roche, M., Haar, J.M. \& Luthans, F. (2014). The role of mindfulness and psychological capital on the wellbeing of leaders. Journal of Occupational Health Psychology, 19(4), 476-489.

Robin, C. (2004). Fear: The history of a political idea. NY: Oxford University press.

Rubin, R.S., Staebler-Tardino, V.M., Daus, C.S., \& Munz, D. (2005). A reconceptualization of the emotional labor construct: On the development of the integrated theory of perceived emotional dissonance and emotional labor. In, Hartel, C.E.J., Zerbe, J. \& Ashkanasy, Eds., Emotions in Organizational Behavior. Mahwah, NJ: Lawrence Erlbaum Associates.

Salovey, P. \& Mayer, J.D. (1990). Emotional intelligence. Imagination, Cognition and Personality, 9(3), 185211

Sanyal, C. \& Rigg, C. (2020, forthcoming). Integrating mindfulness into leadership development. Journal of Management Education, 44, June, 1-22.

SEL is (n.d.). Retreived from https://casel.org/what-is-sel.

SEL: What are the core competence areas and where are they promoted? Retreived from

https://casel.org/core-competencies/

Schlund, J. \& Weissberg, R.P. (May 19, 2020). Leveraging social and emotional learning to support students and families in the time of covid-19. Learning Policy Institute. LPI Blog. https://learningpolicyinstitute.org/blog/leveraging-social-emotional-learning-support-studentsfamilies-covid-19

Smits, S.J. \& Ally, N.E. (2003). “Thinking the unthinkable” - Leadership's role in creating behavioral readiness for crisis management. Competitiveness Review, 13(1), 1-23.

Stacey, R.D. (1995). The science of complexity: An alternative perspective for strategic change processes. Strategic Management Journal, 16(6), 477-495.

Stacey, R.D., Griffin, D. \& Snow, P. (2000). Complexity and management: Fad or radical challenge to systems thinking. London: Routlege.

Stagman-Tyler, D. (2014). Resiliency and the nurse leader: The importance of equanimity, optimism, and perseverance. Nursing Management, 45(6), 46-50.

Stoddard, J. (2020). How resiliency prepares leaders to prevail on battlefields of the future. Journal of Character and Leadership Development, 7(2), 140-153.

Sunindijo, R.Y., Hadikusumo, B.H.W., \& Ogunlana, S. (2007). Emotional intelligence and leadership styles in construction project management. Journal of Management in Engineering, 23(4), 166-170.

Taylor, R.D., Oberle, E, Durlak, J.A. \& Weissberg, R.P. (2017). Promoting Positive Youth Development Through School-Based Social and Emotional Learning Interventions: A Meta-Analysis of Follow-Up Effects. Child Development, 88(4), 1156-1171. https://doi.org/10.1111/cdev.12864

Tennant, C. \& McLean, L. (2001). The impact of emotions on coronary heart disease risk. Journal of Cardiovascular Risk, 8(3), 175-183.

Teo, W.L., Lee, M., \& Lim, WS (2017). The relational activation of resilience model: How leadership activates resilience in an organizational climate. Journal of Contingencies and Crisis Management, $25,136-147$.

Tsai, C., Tsai, L., \& Wang, Y-C. (2011). A study n the relationship between leadership style, emotional intelligence, self-efficacy and organizational commitment: A case study of the banking industry in Taiwan. Journal of Business Management, 5(13), 5319-5329.

Tying, C.M., Amin, H.U., Saad, M.N.M., \& Malik, A.S. (2017). The influences of emotion on learning and memory. Frontiers in Psychology, 8, Article 1454

Uhl-Bien, M. \& Marion, R. (2011). Complexity leadership theory. In Bryman, A., Collinson, D., Grint, K., Jackson, B. \& Uhl-Bien, M., Sage Handbook of Leadership, 468-481. Los Angeles: Sage.

Uhl-Bien, M., Marion, R. \& McKelvey, B. (2007). Complexity leadership theory: Shifting leadership from the industrial age to the knowledge era. The Leadership Quarterly, 18, 298-318.

Van Knippenberg, D. \& Van Kleef, G.A. (2016). Leadership and affect: Moving the hearts and minds of followers. Academy of Management Annals, 10(1), 799-840.

Vitello-Cicciu, J.M. (2003). Nursing Management, 34(10), 28-32.

Walter, F.W., Cole, M.S. \& Humphrey, R.H. (2011). Emotional intelligence: sine qua non of leadership or folderol? Academy of Management Perspectives, 25(1), 45059.

Walumbwa, F.O., Aviolo, B.J., Gardner, W.L., Wernsing, T.S. \& Peterson, S.J. (2008). Authentic leadership: Development and validation of a theory-based measure. Journal of Management, 34(1), 89-126.

Wheatley, M.J. (1992). Leadership and the new science. San Francisco, CA: Berrett-Koehler Publishers.

Williford, A. Fite, P.J., DePaolis, K.J., Cooley, J.L., Hawley, P.H. \& Isen, D. (2019) A Comprehensive Training Initiative for Educators to Develop and Implement Effective Anti-Bullying Policies in K-12 Schools. Journal of Applied School Psychology, 35:2, 146-175, DOI: 10.1080/15377903.2018.1528489

Yukl, G. (2002). Leadership in organizations, $5^{\text {th }}$ edition. Upper Saddle River, NY: Prentice Hall. 


\section{Appendix A - Coping Strategies for Emotionally Adaptable Leaders}

\section{Short term coping:}

- Believe in yourself - Leaders are in their roles for a reason. They were selected to be in charge. People rely on their leaders. When decisions are for the collective good, leaders must learn to believe in and accept their decisions and instincts. In Ginsberg \& Davies (2007) study of the human side of leader decision-making, one business man explained how he knew he had made the right decision, "when I like what I see in the mirror, I know that that I've done what was right" (p. 77). Thoughtful decisions can ease the pain for everyone.

- The need for communication, transparency, sharing - every leadership theory emphasizes the importance of communication and transparency. Leaders need not make decisions by themselves. Communication is healthy for both leaders and employees.

- Rely on your social circle - friends, family, professional colleagues are all important when facing difficult and emotional circumstances. Reiff, Gerber \& Ginsberg (1997) referred to this support system as one's social ecology. Having supportive persons to share ideas with and rely on is important for any leader.

- Take care of yourself -The leader's that Ginsberg \& Davies (2007) studied were adamant that leaders need make time for themselves to, "diffuse the emotional strain" (p. 92). Following healthy habits, exercising, laughing, getting enough sleep, working with support networks can all help (see also, Ginsberg \& Multon, 2011).

- Don't panic - In a technology-driven world, making a rash judgement, for example -hitting the "send" button before considering the ramifications in an e-mail reply - can exacerbate a situation that needs be diffused and resolved. Avoid panic-driven responses.

- Own your face - the research on emotional contagion emphasized how emotions can be transmitted. As leader, you give off cues about your emotional state. Your expressions as leader have meaning to those you interact with and can affect their behavior.

Long-term thriving:

- Acceptance - Being in charge is hard. Decisions a leader makes have an impact. Preparing for a hard meeting or decision can be very difficult. There will be times that leaders will evoke emotions within themselves and others. The point is simple - emotions and stress are part of the job. Fighting against or brushing aside feeling emotions is foolish. Considering ways to plan, strategize and react to the inputs are key.

- Emotional sensitivity - derived directly from concepts in EI that focus on understanding emotions of those in the work place. Learning to be sensitive to the needs and concerns of employees, and developing policy and making decisions with these in mind, can help dampen emotional turmoil.

- Identify and beware of emotional pot holes - There are specific behaviors, actions, decisions points, etc. that affect each person differently. Ginsberg \& Davies (2007) found that financial and personnel decisions were the most common areas sparking emotional uneasiness. Leaders need identify the specific issues that affect them most, and consider ways to deal with these things that tickle their fancy.

- Accept change - No organization is static. For example, few if any leader today is pleased about the pandemic, but in normal times, employees come and go and budgets fluctuate. Things happen. Resisting change is senseless given the uncertainty that the research on complex adaptive systems identifies. Embrace change, use it as a force to strengthen the organization. Economists refer to the "sunk-cost fallacy." Too many leaders invest time, energy and money in something and refuse to move on. Leaders in Ginsberg \& Davies' (2007) study cautioned against becoming stuck in your ways. Change is inevitable and should be a tool for success. Having an emotional plan for dealing with the stresses to come can be a proactive way to thrive (Caruso \& Salovey, 2004)

- Don't give up - Drawn from the research on resilience, grit, and hardiness, great leaders persist even in the most difficult of circumstances. Knowing how much employees and colleagues rely on the leader can be challenging, but invigorating as well.

- Give yourself a break - to err is human. All leaders make mistakes. Hall of fame baseball players typically failed seven out of ten times they got up to bat. The great ones don't allow the failure to hold them back. Leaders, too, need understand they will make mistakes. Learning from them, and moving on, should be the goal. 
